\title{
Analisis Kinerja Natural Draft Cooling Tower di Unit Kilang Pusat Pengembangan Sumber Daya Manusia Minyak dan Gas Bumi
}

\author{
Anwar Setiya Anugrah"), Fadel Aji Firmansyah"), Raka Ade Ilhamsyah"1), \\ Mukhamad Faeshol Umam²) \\ 1) Universitas Muhammadiyah Surakarta \\ 2) Pusat Pengembangan SDM Minyak dan Gas Bumi \\ Email: anwarsetiya08@gmail.com
}

\begin{abstract}
Abstrak Cooling Tower seperti efisiensi, make up water dan juga kapasitas perpindahan panas dari Unit Cooling Tower - Dalam penulisan ini, peneliti menggunakan metode penelitian langsung di lapangan untuk mengetahui fenomena yang terjadi pada Cooling Tower. Sedangkan kinerja Natural draft Cooling Tower dihitung menggunakan metode perhitungan. Hasil penelitian menunjukkan efektifitas aktual Cooling Tower adalah 79,4 \%, kapasitas pendinginan $2477,477 \mathrm{Kj} / \mathrm{s}$, dan nilai make-up water 2,37 $\mathrm{m} 3 / j a m$. Hal ini menunjukkan kinerja dari Cooling Tower sudah menurun jika dibandingkan desain awal efektivitas Cooling Tower adalah sebesar $83 \%$.
\end{abstract}

Pusat Pengembangan Sumber Daya Manusia Minyak dan Gas Bumi (PPSDM Migas) mengelola unit kilang yang digunakan untuk pengolahan minyak mentah dari P.T. Pertamina Eksplorasi dan Produksi. Minyak mentah tersebut diolah menjadi produk-produk hasil olahan yang meliputi solven, solar dan residu. Sebelum produk olahan ini disimpan di tangki penampungan, harus didinginkan menggunakan condenser dan cooler untuk mengubahnya menjadi fasa cair. Air panas dari condenser dan cooler ini kemudian didinginkan menggunakan Natural draft Cooling Tower . Penelitian tentang Natural draft Cooling Tower di PPSDM Migas ini bertujuan untuk mencari parameter-parameter yang mempengaruhi kinerja Natural draft

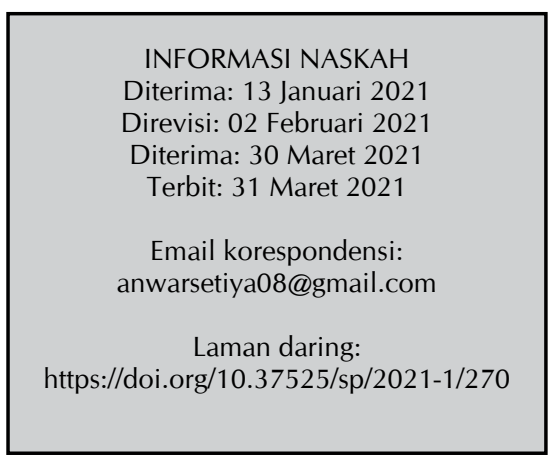

Kata kunci: Cooling Tower, Efektivitas, Make-up water, Kapasitas Pendingin

\section{Pendahuluan}

PPSDM Migas mempunyai unit pengolahan minyak bumi yang mengolah crude oil dan P.T. Pertamina Eksplorasi dan Produksi menjadi beberapa produk yaitu solven, solar dan residu. Dalam pengoperasiannya, unit pengolahan menggunakan condenser dan cooler untuk meng- 
ubah fase produk dan mendinginkannya sebelum disimpan di tangki produk. Air pendingin cooler disirkulasikan di Natural draft Cooling Tower sebagai alat penukar panas di kilang dan ulititinya.

Cooling Tower ini sudah beroperasi lama sehingga perlu diteliti apakah alat ini sudah cukup efisien dalam pengoperasiannya. Selain itu, kapasitas pendinginan Natural draft Cooling Tower perlu dihitung dan dibandingkan dengan kapasitas desain awal, sehingga bisa diketahui apakah Cooling Tower ini masih mencukupi untuk operasi maksimum kilang. Selanjutnya, kebutuhan make-up water juga akan dihitung untuk mengukur kemampuan pompa dan kebutuhan airnya.

Penelitian ini dilakukan di PPSDM Migas pada bulan Desember 2020. Beberapa asumsi yang digunakan yaitu:

1. Kecepatan di udara diasumsikan sama dengan data dari BMKG, karena tidak memiliki alat ukur untuk mengukur secara tepat.

2. Suhu yang diukur dianggap sama di semua titik pada kolam air yang panas maupun dingin.

3. Suhu dari unit kilang menuju kolam panas diukur dari pipa pada penerima, dan suhu dari kolam dingin menuju unit kilang diukur dari pipa pada pompa pengirim.

4. Pengambilan data dilakukan pada siang hari dengan kondisi operasi unit pengolahan dengan kapasitas sebesar 300 kL/hari.

\section{Tinjauan Pustaka}

Cooling Tower adalah suatu system refrigrasi yang melepaskan kalor ke udara. Cooling Tower bekerja dengan melepaskan kalor ke udara dengan cara memberikan kontak antara air dengan udara. Luas permukaan air yang besar dibentuk dengan cara menyemprotkan air atau memercikkan air ke bawah menuju sekat-sekat (packing). Fungsi packing adalah untuk membuat luasan air yang berkontak dengan udara menjadi lebih besar sehingga proses perpindahan kalor akan semakin lebih besar (Herlambang, 2014).

Tugas utama Cooling Tower adalah membuang panas ke atmosfer. Cooling Tower memiliki skema kerja seperti pada gambar dibawah ini. 


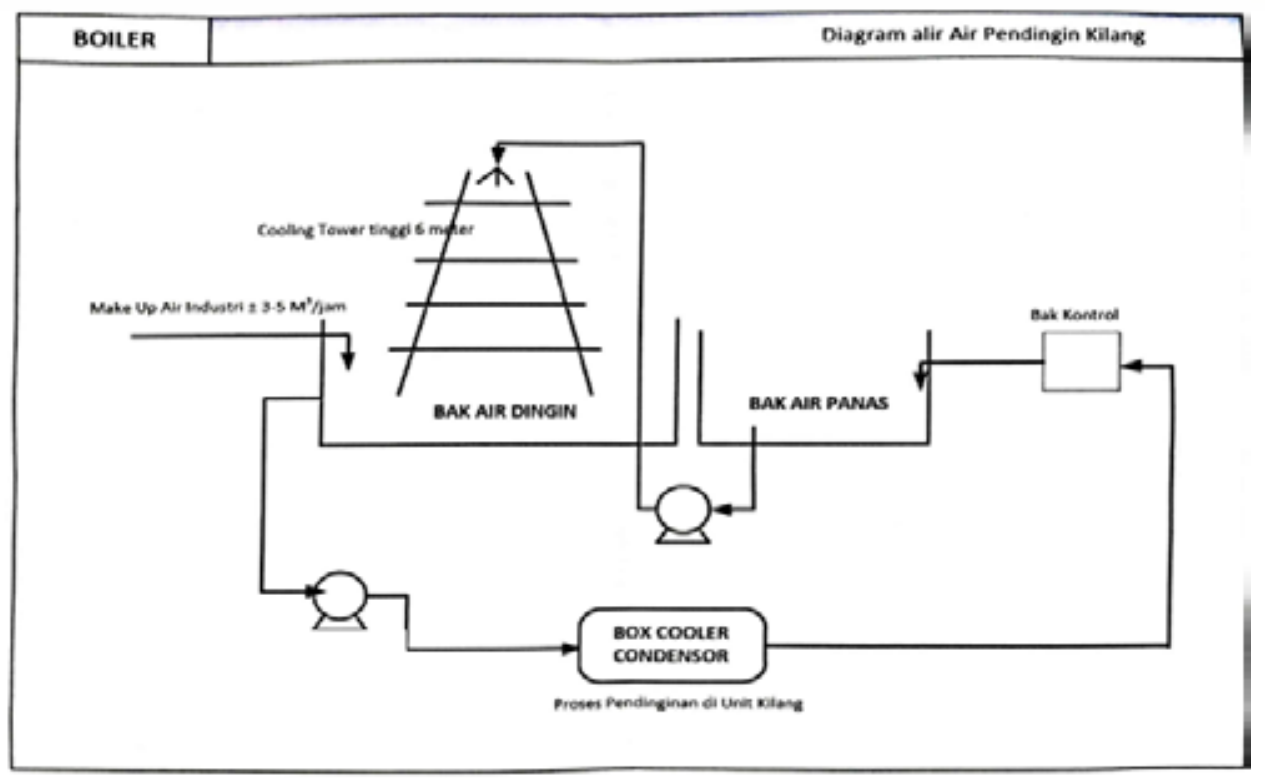

Gambar 1. skema kerja Cooling Tower (PPSDM Migas, 2020)

Kemampuan Cooling Tower dalam menghasilkan air pendingin biasanya dinyatakan dalam range dan approach seperti yang terlihat pada gambar dibawah ini.

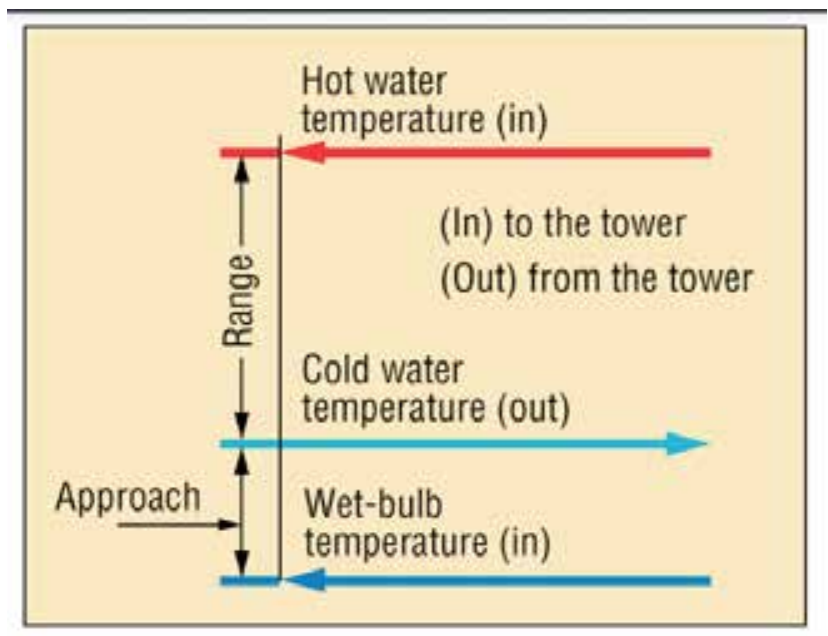

Gambar 2. Range dan Approach Temperature pada Cooling Tower (Burreau Of Energy Efficiency).

Range adalah perbedaan suhu antara tingkat suhu air masuk Cooling Tower dengan tingkat suhu air yang keluar Cooling Tower atau selisih antara suhu air panas dan suhu air dingin. Approach adalah perbedaan antara suhu air keluar Cooling Tower dengan suhu bola basah udara yang masuk atau selisih antara suhu air dingin dan suhu bola basah (wet bulb) dari udara (Pranto Busono, 2020).

Sedangkan Natural draft Cooling Tower adalah jenis Cooling Tower yang tidak menggunakan kipas (fan). Aliran udaranya bergantung semata - mata pada tekanan dorong alami. Pada Natu- 
ral draft Cooling Tower tidak ada bagian yang bergerak, udara mengalir ke atas akibat adanya perbedaan massa jenis antara udara atmosfer dengan udara kalor lembab di dalam Cooling Tower yang bersuhu lebih tinggi daripada udara atmosfer di sekitarnya.

Natural draft Cooling Tower mempunyai sistem distribusi air panas yang disemprotkan secara merata ke kisi - kisi, lubang - lubang atau batang - batang horizontal pada sisi menara yang disebut isian. Udara masuk dari luar menara melalui kisi-kisi yang berbentuk celah - celah horizontal yang terpancang pada sisi menara.

\section{Metode Penelitian}

Metode yang digunakan dalam pennelitian ini adalah pengambilan data langsung kemudian diolah dengan perhitungan. Tahapan-tahapan dalam penelitian ini meliputi studi literature tentang Cooling Tower dengan mencari di internet, buku, jurnal, dan lain-lain. Tahapan selanjutnya adalah pengambilan data pada Cooling Tower unit kilang PPSDM migas. Data manufaktur yang diperoleh dari arsip PPSDM Migas merupakan data awal atau rancangan awal Cooling Tower seperti terlihat pada gambar 3. Dari pengambilan data di lapangan, didapatkan datadata sebagai berikut:

Suhu air sebelum didinginkan $\left(\mathrm{T}_{1 \mathrm{t}}\right): 38^{\circ} \mathrm{C}$

Suhu air setelah didinginkan $\left(\mathrm{T}_{2 \mathrm{t}}\right): 28^{\circ} \mathrm{C}$

Suhu Wet bulb $\left(\mathrm{T}_{\mathrm{wb}}\right) \quad: 26^{\circ} \mathrm{C}$

Make-up water

$: 3 \mathrm{~m}^{3} / \mathrm{jam}$

Volume bak air dingin

$: 291,9 \mathrm{~m}^{3}$

Volume air di bak air dingin

$: 235 \mathrm{~m}^{3}$

Volume bak air panas

: 73,07 $\mathrm{m}^{3}$

Volume air di bak air panas

$: 200 \mathrm{~m}^{3}$

Sedangkan untuk data aktual atau data lapangan, diperoleh sebagai berikut,

Suhu air sebelum didinginkan $\left(\mathrm{T}_{1 \mathrm{a}}\right): 35,7^{\circ} \mathrm{C}$

Suhu air setelah didinginkan $\left(\mathrm{T}_{2 \mathrm{a}}\right) \quad: 31^{\circ} \mathrm{C}$

Suhu Wet bulb $\left(\mathrm{T}_{\mathrm{wb}}\right) \quad: 26^{\circ} \mathrm{C}$

Tekanan pompa menuju Cooling Tower $\left(\mathrm{P}_{1}\right)$

Tekanan Udara $\left(\mathrm{P}_{2}\right)$

$: 100800 \mathrm{~Pa}$

Diameter pipa (D)

: $0,1778 \mathrm{~m}$ 


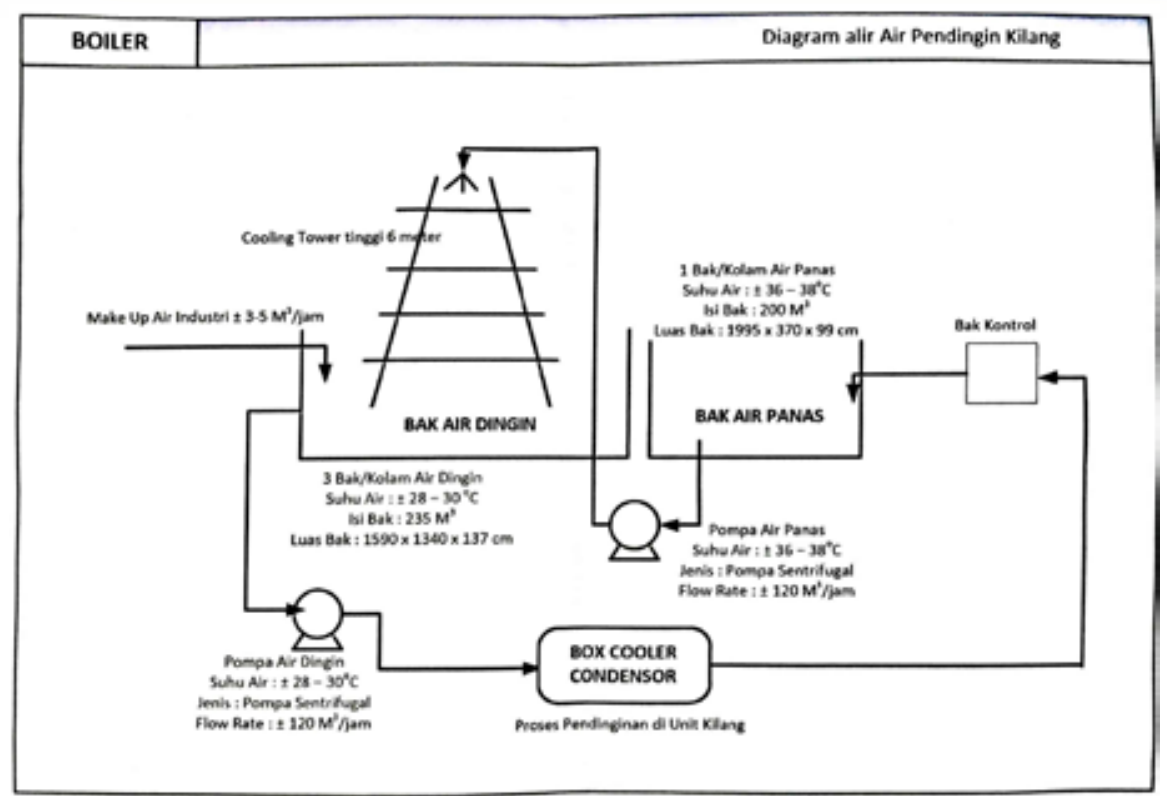

Gambar 3. Desain awal Natural draft Cooling Tower (PPSDM, 2020)

\section{Hasil Penelitian dan Pembahasan}

\section{Perhitungan menggunakan data desain awal}

\section{Efektivitas Cooling Tower}

Untuk menghitung efektifitas teoritis, diperlukan data teoritis suhu air sebelum didinginkan, suhu air setelah didinginkan, dan suhu wet bulb. Data tersebut digunakan untuk mencari Range dan Approach.

$$
\begin{array}{ll}
\text { Range } & =\text { suhu air panas }\left(\mathrm{T}_{1 \mathrm{t}}\right)-\text { suhu air dingin }\left(\mathrm{T}_{2 \mathrm{t}}\right) \\
& =38{ }^{\circ} \mathrm{C}-28{ }^{\circ} \mathrm{C} \\
& =10{ }^{\circ} \mathrm{C} \\
\text { Approach } & =\text { suhu air dingin }\left(\mathrm{T}_{2 \mathrm{t}}\right) \text { - suhu wet bulb }\left(\mathrm{T}_{\mathrm{wb}}\right) \\
& =28{ }^{\circ} \mathrm{C}-26{ }^{\circ} \mathrm{C} \\
& =2{ }^{\circ} \mathrm{C} \\
\text { Efektivitas } & =\left(\frac{\text { range }}{\text { range+approach }}\right) \\
& =\left(\frac{10}{10+2}\right) \times 100 \% \\
& =83 \%
\end{array}
$$




\section{Make-up water}

Data Make-up Water secara teoritis didapat dari desain awal Cooling Tower. Secara ideal, Make-up Water Natural draft Cooling Tower adalah 3 m3/jam

\section{Kapasitas Pendinginan}

Untuk mengetahui berapa kapasitas pendinginan pada Cooling Tower maka berapa laju aliran massanya. Dimana pada data teori debit sudah diketahui sebesar 120 m3/jam

\section{a. Laju Aliran Massa Air}

Berdasarkan grafik densitas air (Lampiran 2.), Massa jenis air pada suhu $38^{\circ} \mathrm{C}=993 \mathrm{~kg} / \mathrm{m} 3$, didapatkan dari grafik massa jenis air.

\section{$L=Q_{\text {air }} x \rho_{\text {air }}$ pada suhu air masuk}

$L=120 \frac{\mathrm{m}^{3}}{\mathrm{jam}} X 993 \mathrm{~kg} / \mathrm{m}^{3}$

$L=119160 \frac{\mathrm{kg}}{\mathrm{jam}}$

$L=33,1 \frac{\mathrm{kg}}{\mathrm{s}}$

b. Kapasitas Pendinginan

$$
\begin{aligned}
& Q=\dot{\mathrm{m}} \times \operatorname{Cp} \times \Delta \mathrm{T} \\
& Q=33,1 \frac{\mathrm{kg}}{\mathrm{s}} \times 4,18 \frac{\mathrm{kJ}}{\mathrm{kgK}} \times 10 \mathrm{~K} \\
& Q=1383,58 \frac{\mathrm{kJ}}{\mathrm{s}}
\end{aligned}
$$

Maka dapat diketahui kapasatas pendinginan pada unit Cooling Tower sebesar 1383,58 kJ/s

\section{Perhitungan menggunakan data aktual}

\section{Efektifitas Cooling Tower}

Untuk menghitung efektivitas aktual, diperlukan data aktual dari pengukuran langsung seperti suhu air sebelum didinginkan, suhu air setelah didinginkan, dan suhu wet bulb. Data tersebut digunakan untuk mencari Range dan Approach.

$$
\text { Range } \quad \begin{aligned}
= & \text { suhu air panas }\left(\mathrm{T}_{1 \mathrm{a}}\right)-\text { suhu air dingin }\left(\mathrm{T}_{2 \mathrm{a}}\right) \\
& =35,7{ }^{\circ} \mathrm{C}-28{ }^{\circ} \mathrm{C}
\end{aligned}
$$




$$
\begin{aligned}
& =7,7^{\circ} \mathrm{C} \\
\text { Approach } & =\text { suhu air dingin }\left(\mathrm{T}_{2 \mathrm{a}}\right)-\text { suhu wet bulb }\left(\mathrm{T}_{\mathrm{wb}}\right) \\
& =28{ }^{\circ} \mathrm{C}-26{ }^{\circ} \mathrm{C} \\
& =2{ }^{\circ} \mathrm{C} \\
\text { Efektivitas } & =\left(\frac{\text { range }}{\text { range+approach }}\right) \times 100 \% \\
& =\left(\frac{7,7}{7,7+2}\right) \times 100 \% \\
& =79,4 \%
\end{aligned}
$$

\section{Make up Water}

Untuk mengetahui berapa Make-up Water, diperlukan beberapa data yaitu evaporation loss, drift loss, dan blowdown. Untuk mendapatkan data-data tersebut, kita perlu menghitung debit air.

Untuk mengetahui berapa debit airnya, perlu dekitahui terlebih dahulu berapa nilai koefisisen kekasaran pipa $(f)$ untuk mengetahui berapa besarnya kecepatan air (v).

a. Nilai kekasaran pipa (f)

Dimana nilai didapat pada tabel Lewis F. Moody dengan nilai $\varepsilon=0,00026 \mathrm{~m}$

$$
\begin{aligned}
& \frac{1}{\sqrt{f}}=1,74-2 \log \left(\frac{2 \varepsilon}{D}\right) \\
& \frac{1}{\sqrt{f}}=1,74-2 \log \left(\frac{2 \times 0,00026}{0,1778}\right) \\
& f=0,02
\end{aligned}
$$

\section{b. Debit}

Saat koefisien kekasaran pipa sudah didapakan maka nilai kecepatan air bisa di cari. Asumsikan panjang pipa $25 \mathrm{~m}$

$$
\begin{aligned}
& v=\sqrt{\frac{2 \Delta P}{\rho\left(4 f \frac{\Delta x}{D}+1\right)}} \\
& v=\sqrt{\left.\frac{2(411879-100800)}{25 / 0,1778}+1\right)} \\
& v=3,11 \frac{m}{s}
\end{aligned}
$$


Debit diperoleh dengan rumus $\mathrm{W}_{\mathrm{c}}=\mathrm{V} . \mathrm{A}$

Dimana: $\mathrm{A}=$ luas penampang pipa

$$
\begin{aligned}
& A=\frac{\pi}{4} x D^{2} \\
& A=\frac{\pi}{4} x 0,1778^{2} \\
& A=0,0248 \mathrm{~m}^{2}
\end{aligned}
$$

Jika kecepatan (v) dan luas penampang pipa (A) sudah diketahui maka debit bias dicari dengan

$$
\begin{aligned}
W c & =A . v \\
W c & =0,0248 \times 3,11 \\
W c & =0,077128 \frac{\mathrm{m}^{3}}{\mathrm{~s}} \\
W c & =0,077128 \frac{\mathrm{m}^{3}}{\mathrm{~s}} \times 3600 \\
W c & =277,66 \frac{\mathrm{m}^{3}}{\mathrm{jam}}
\end{aligned}
$$

c. Evaporation Loss

Evaporation loss adalah besarnya kehilangan air akibat penguapan.

Untuk mencari evaporation loss digunakan rumus

$$
\begin{aligned}
W e & =w c \times 0,00085 \times(T 1 a-T 2 a) \\
W e & =277,66 \times 0,00085 \times 7,7 \\
W e & =1,81 \frac{\mathrm{m}^{3}}{\mathrm{jam}}
\end{aligned}
$$

d. Menghitung kehilangan akibat drift loss Drift loss (Wd)

$$
\begin{aligned}
& W d=0,2 \% x W c \\
& W d=0,2 \% x 277,66
\end{aligned}
$$




$$
W d=0,56 \frac{\mathrm{m}^{3}}{j a m}
$$

Setelah didapatkan nilai evaporation loss, drift loss dan blow down maka Make-up water akan diketahui

$$
\begin{aligned}
\text { Make }- \text { up Water } & =\text { We }+ \text { Wd } \\
& =1,81+0.56 \\
& =2,37 \frac{m^{3}}{j a m}
\end{aligned}
$$

Maka secara aktual make-up water diperoleh sebesar 2,37 m³/jam

\section{Kapasitas Pendinginan}

Untuk mengetahui berapa kapasitas pendinginannya secara aktual maka harus diketahui laju aliran massa secara aktual yaitu,

Laju aliran massa air (L)

Berdasarkan grafik densitas air (Lampiran 2.), Massa jenis air pada suhu $35,7^{\circ} \mathrm{C}$ $=998 \mathrm{~kg} / \mathrm{m}^{3}$

$$
L=Q_{\text {air }} x \rho_{\text {air }} \text { pada suhu air masuk }
$$

$$
\begin{aligned}
L & =277,66 \frac{\mathrm{m}^{3}}{\mathrm{jam}} \times 998 \mathrm{~kg} / \mathrm{m}^{3} \\
L & =277104,68 \frac{\mathrm{kg}}{\mathrm{jam}} \\
& \mid \\
L & =76,97 \frac{\mathrm{kg}}{\mathrm{s}}
\end{aligned}
$$

Kapasitas pendinginan $(\mathrm{Q})$

$$
\begin{aligned}
& Q=\dot{\mathrm{m}} \times \mathrm{Cp} \times \Delta \mathrm{T} \\
& Q=76,97 \frac{\mathrm{kg}}{\mathrm{s}} \times 4,18 \frac{\mathrm{kJ}}{\mathrm{kgK}} \times 7,7 \mathrm{~K} \\
& Q=2477,477 \frac{\mathrm{kJ}}{\mathrm{s}}
\end{aligned}
$$


Kapasitas pendinginan Cooling Tower secara aktual adalah 2477,477 kJ/s

Tabel 1. Perbandingan hasil antara desain awal dengan kondisi aktual

\begin{tabular}{|l|c|c|}
\hline Parameter & Manufaktur & Aktual \\
\hline Efektivitas & $83 \%$ & $79,4 \%$ \\
\hline Kapasitas & $1383,58 \mathrm{kj} / \mathrm{s}$ & $2477,477 \mathrm{kj} / \mathrm{s}$ \\
\hline Make up & $3 \mathrm{~m}^{3} / \mathrm{jam}$ & $2,37 \mathrm{~m}^{3} / \mathrm{jam}$ \\
\hline Range & $10^{\circ} \mathrm{C}$ & $7,7^{\circ} \mathrm{C}$ \\
\hline Approach & $2^{\circ} \mathrm{C}$ & $2^{\circ} \mathrm{C}$ \\
\hline
\end{tabular}

Hasil dari perhitungan yang dilakukan ditampilkan dalam tabel 1. Dari tabel 1, dapat dilihat bahwa efektivitas dan make up water kondisi aktual lebih kecil daripada kondisi desain awal. Sedangkan kapasitas pendinginan kondisi aktualnya lebih besar daripada kondisi desain awal.

\section{Pembahasan}

\section{Efektivitas}

Efektivitas adalah perbandingan Range dan selisih Range dan Approach. Range merupakan perbedaan suhu sebelum didinginkan dan setelah didinginkan sedangkan approach merupakan perbedaan suhu setelah didinginkan dan suhu wet bulb. Perbandingan ini dapat menunjukkan kemampuan pendinginan Natural draft Cooling Tower PPSDM Migas dalam persen.

Efektivitas Natural draft Cooling Tower secara teori dianggap optimal yaitu 83\%. Sedangkan perhitungan efektivitas secara aktual yaitu $79,4 \%$. Hal ini membuktikan bahwa Natural draft Cooling Tower dalam keadaan optimal karena efektivitas secara aktual kurang lebih hampir sama dengan efektivitas secara teori.

Perubahan suhu air cukup besar dapat dipengaruhi oleh suhu lingkungan, kecepatan angin yang berhembus, tempat pengambilan sampel suhu air, dan kecepatan aliran airnya. Jadi keadaan Natural draft Cooling Tower PPSDM masih baik (optimal), walaupun jika dilihat bangunan Natural draft Cooling Tower sudah banyak bagian yang berkarat dan ditumbuhi lumut.

\section{Kapasitas Pendinginan}

Nilai kapasitas pendinginan menunjukan banyaknya energi atau perpindahan panas tiap detik pada air yang keluar. Nilai tersebut dipengaruhi oleh debit dan perubahan suhu. Semakin tinggi perubahan suhu maka kapasitas pendinginan semakin tinggi. Nilai kapasitas yang tinggi menunjukan baik tidaknya kemampuan pendinginan Cooling Tower .

Kapasitas pendinginan secara teori dianggap optimal yaitu 1383,58 kj/s. sedangkan kapasitas pendinginan secara aktual didapat $2477,477 \mathrm{kj} / \mathrm{s}$. Dari kedua perhitungan tersebut, kapasitas pendinginan secara aktual melebihi keadaan optimal. Hal ini mungkin dapat terjadi karena 
jumlah air yang lebih besar daripada jumlah air saat penggunaan optimal tergantung dari kebutuhan air yang diperlukan untuk pengolahan minyak, dan berapa pompa yang diaktifkan pada Cooling Tower sehingga debit pada Cooling Tower lebih besar dibandingkan dengan desain optimal.

Jika debit secara aktual adalah $120 \mathrm{~m}^{3} / \mathrm{jam}$ (sama dengan desain optimal) nilai kapasitas pendinginan secara aktual seharusnya lebih rendah dari keadaan optimal karena perbedaan suhu yang lebih sedikit daripada desain optimal. Ini menunjukan bahwa kapasitas pendinginan pada Natural draft Cooling Tower PPSDM Migas mengalami sedikit penurunan kemampuan dalam peninginan air. Debit yang tinggi menunjukan penggunaan air yang terlalu boros.

\section{Kemampuan Natural draft Cooling Tower Keadaan Unit Kilang Maksimum}

Unit kilang PPSDM MIGAS mempunyai kapasitas pengolahan minyak mentah sebesar $600 \mathrm{~kL} /$ hari. Pada proses pengolahan minyak, diperlukan kondensor dan cooler untuk mendinginkan produk sebelum disimpan ke dalam tangki. Natural draft Cooling Tower di PPSDM Migas menjadi salah satu alat yang berperan dalam mendinginkan air dari kondensor dan cooler yang panas ketika menyerap suhu dari minyak. Ketika kilang bekerja secara maksimal, dibutuhkan air dengan jumlah yang besar. Oleh karena itu Natural draft Cooling Tower di PPSDM Migas juga harus bekerja secara maksimal agar dapat menampung dan mengirim air dengan jumlah yang besar.

Dengan diketahuinya efektivitas dan kapasitas pendingin, pada keadaan unit kilang yang maksimum Natural draft Cooling Tower masih bisa beroperasi dengan baik. Nilai efektivitas menunjukan bahwa kemampuan mendinginkan Cooling Tower sudah menurun namun penurunannya tidak terlalu signifikan meski nilai efektivitas juga bergantung pada faktor lingkungan terutama suhu. Begitu juga dengan kapasitas pendinginan, nilai kapasitas pendinginan secara aktual lebih tinggi dari desain optimal. Jika debit desain awal dan keadaan aktual sama, maka kapasitas pendinginan secara aktual akan menunjukan kemampuannya dalam mendinginkan air menurun tetapi tidak signifikan penurunannya.

Karena kebutuhan air meningkat, maka debit air juga ikut meningkat. Dengan keaadaan yang sekarang, Cooling Tower masih bisa beroperasi secara maksimum karena kemampuan pendinginan yang masih baik. Meskipun begitu, debit air yang tinggi bisa membahayakan konstruksi dan komponen dari Natural draft Cooling Tower PPSDM Migas karena banyak sekali komponen yang sudah tidak layak pakai seperti kayu-kayu yang sudah lapuk dan besi yang berkarat. 


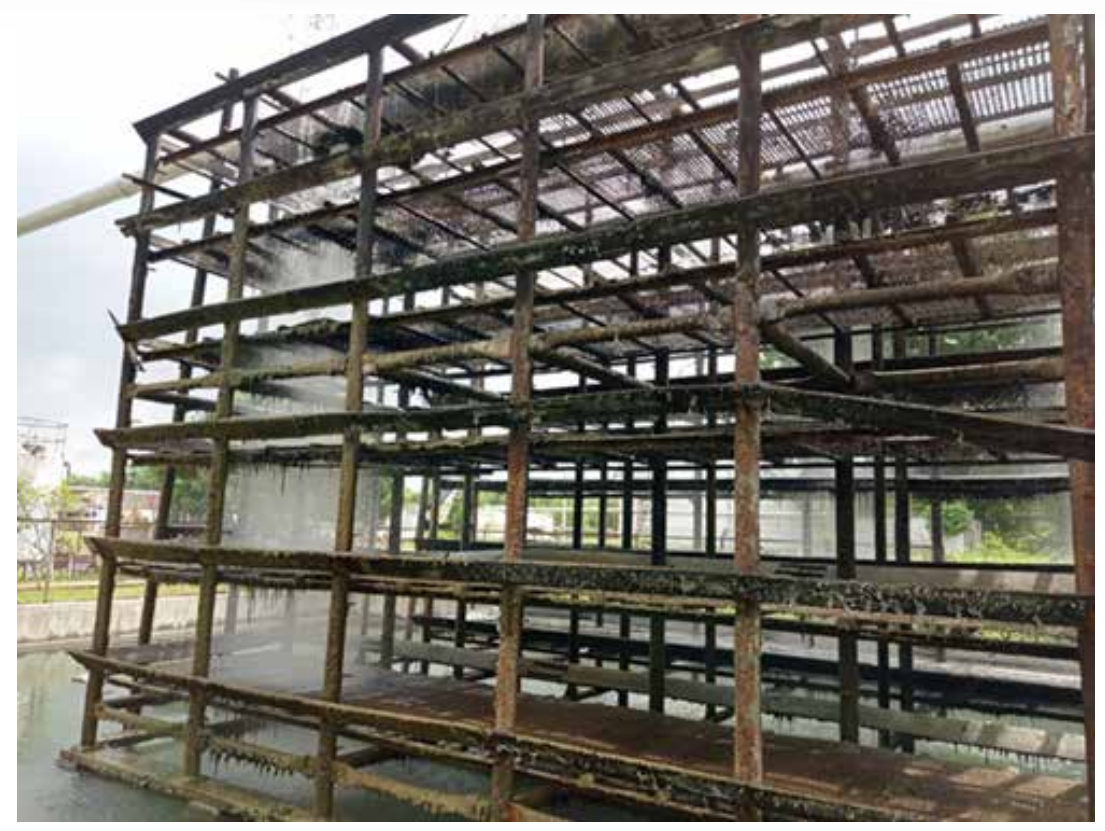

Gambar 4. Natural draft Cooling Tower PPSDM Migas

\section{Make-up Water}

Make-up water merupakan kebutuhan air yang diperlukan akibat adanya kehilangan air ketika proses pendinginan menggunakan Natural draft Cooling Tower . Nilai make-up water menunjukan berapa kehilangan air ketika proses pendinginan terjadi. Jika nilai make-up water tinggi, maka Cooling Tower tersebut dalam keadaan tidak baik karena kehilangan air tersebut perlu ditambal atau diisi dengan nilai yang sama. Penambahan air yang banyak tentu mengindikasikan kebutuhan air yang boros atau berlebihan.

Make-up water yang dibutuhkan secara optimal sebesar $3 \mathrm{~m} 3 /$ jam untuk menambal kehilangan air karena evaporasi dan drift loss. Sedangkan make-up water yang dibutuhkan secara aktual adalah $1,73 \mathrm{~m} 3 / \mathrm{jam}$. Hal ini membuktikan pada saat operasional tidak banyak kehilangan air sehingga hanya membutuhkan penambalan air lebih sedikit daripada keadaan optimal yang sudah direncanakan.

Keadaan ini terjadi karena faktor lingkungan, cuaca, dan suhu yang dibawa air dari unit kilang menuju Cooling Tower tidak terlalu panas sehingga kehilangan air tidak banyak.

\section{Kesimpulan}

Dari hasil perhitungan dan pembahasan didapatkan kesimpulan sebagai berikut:

1. Efektivitas aktual pada Natural draft Cooling Tower dalam keadaan operasional tidak mencapai efektivitas optimal (83\%). Efektivitas aktual yang didapat dari perhitungan sebesar 48,4\%. Hal ini menunjukan bahwa Cooling Tower tidak dalam keadaan optimal dimana pendinginan suhu mengalami penurunan.

2. Kapasitas pendinginan aktual yang melebihi keadaan optimal. Kapasitas pendinginan seca- 
ra optimal sebesar 1383,58 kj/s. Sedangkan kapasitas pendinginan aktual sebesar 1572,46 $\mathrm{kj} / \mathrm{s}$. Ini menunjukan bahwa nilai kapasitas pendinginan tidak selalu sama atau kurang dari nilai keadaan optimal. Hal ini mungkin dapat terjadi karena debit air aktual lebih besar daripada saat penggunaan optimal tergantung dari kebutuhan air yang diperlukan untuk pengolahan minyak.

3. Berdasarkan pembahasan diatas, Natural draft Cooling Tower sebagai objek penelitian tidak dalam keadaan optimal karena efektivitas dan kapasitas pendinginan yang tidak optimal. Dengan keadaan unit kilang pengolahan minyak yang maksimum yaitu 600 kL/hari, Natural draft Cooling Tower akan terbebani.

4. Nilai Make-up water aktual yang lebih sedikit dari keadaan optimal. Make-up water secara optimal sebesar $3 \mathrm{~m} 3 / \mathrm{jam}$. Sedangkan make-up water aktual sebesar 1,73 m3/jam. Hal ini menunjukan bahwa tidak banyak kehilangan air sehingga penambalan air lebih sedikit daripada desain optimal.

\section{Daftar Pustaka}

Bureau of Energy Efficiency. (t.thn.). Diambil kembali dari https://beeindia.gov.in/sites/default/ files/3Ch7.pdf

Herlambang, R. (2014). Diambil kembali dari eprints UNDIP: http://eprints.undip.ac.id/44134/3/ BAB_II.pdf

Pranto Busono, S. P. (2020). ANALISA KEBUTUHAN MAKE UP WATER COOLING TOWER. Buletin Pengelolaan Reaktor Nuklir, 38-44.

Putra, R. S. (2015). ANALISA PERHITUNGAN BEBAN COOLING TOWER. JURNAL TEKNIK MESIN, 56.

PPSDM Migas (2020). Standard Operating Prosedur Cooling Tower Unit Pengolahan Minyak Bumi. Pusat Pengembangan Sumber Daya Manusia Minyak dan gas Bumi. Cepu. 